\title{
Doctors and torture: the police surgeon
}

\author{
Stanley H Burges Ipswich, Suffolk
}

\begin{abstract}
Author's abstract
Much has been written by many distinguished persons about the philosophical, religious and ethical considerations of doctors and their involvement with torture. What follows will not have the erudition or authority of the likes of St Augustine, Mahatma Gandi, Schopenhauer or Thomas Paine. It represents the views of a very ordinary person; a presumption defended by the submission that many very ordinary persons have been, and will be, instruments for effecting, assisting or condoning the physical or mental anguish of others.

As practitioners of medicine, we are particularly vulnerable, since our particular knowledge and our privileged position may be so easily abused - to the detriment of others.

Those of us who practice clinical forensic medicine have even greater responsibility by virtue of our daily contact with the enforcement of law, criminal procedure, and the machinations of the judiciary. We are thus particularly well placed to monitor, encourage or discourage the occurrence of evil practices within the community.

It is imperative, therefore, that the ordinary doctor should be cognisant of, and be party to, a code of conduct formulated by his peers and having reference to his obligations as a citizen, and doctor, and to his ability to manipulate human activity. Forensic physicians have further discretionary powers as arbiters in the marriage of the art and ethics of healing with the principles and practice of justice.
\end{abstract}

\section{Introduction}

For all practical purposes, all forensic physicians in the United Kingdom have a contractual arrangement with a police authority; and, since the formation of a national police force almost a century and a half ago, have been known as police surgeons. In spite of the title, a doctor so employed retains his professional independence and, with few exceptions, performs his duties on a part time basis. It is acknowledged by police and police surgeons alike that a partial police surgeon is a liability to society, an embarrassment to his profession, and an encumbrance to the employing police authority. An expression of this impartiality is seen in Northern Ireland where, in spite of his time honoured title, the police surgeon is now known as a Forensic Medical Officer.

Events have shown that the police forces of a country are the most likely to become the first to be aware of, or the agents of, the torture of its citizens. For this reason, police surgeons in the United Kingdom have given no little attention to the implications of their association with law enforcement. We earnestly hope that we will never become experts. We readily acknowledge that few of us have had our convictions tempered and tested by fear, political strife, poverty, religious intolerance or racial prejudice. We also readily acknowledge that accusations of self-righteousness may be levelled at us by those living with this malignancy. This should not, and I trust, will not, detract from our determination to fore-arm ourselves and thus be the better equipped to combat the first signs of the disease. Indeed, it may be argued that if our peers in Germany, Chile, South Africa, Russia, Greece, Iran, and so many other places, had been afforded the luxury of pre-meditated concerted action, at least some of the results may have been different.

It is convenient to view the subject under five main headings:

a) An acceptance of basic ethical principles

b) An awareness of the extent of the evil

c) The recognition of the assailants

d) The recognition of victims

e) The determination of a course of action

\section{Acceptance of basic ethical principles}

The basic ethical principles have been developed since the time of Hippocrates. In the context of torture, guidelines were initiated by the British Medical Association in 1972 and adopted by the World Medical Association in 1975 . They are usually referred to as the Tokyo Declaration and certain sections are worth quoting.

Torture is defined as the deliberate, systematic or wanton infliction of physical or mental suffering by one or more persons acting alone or on the orders of any authority, to force another person to yield information, to make a confession, or for any other reason.

The doctor shall not countenance, condone or participate in the practice of torture or other forms of cruel, inhuman or degrading procedures, whatever the offence of which the victim of such procedures is suspected, accused or guilty, and whatever the victim's beliefs or motives, and in all situations, including armed conflict and civil strife.

The World Medical Association will support, and should encourage, the international community, the 
National Medical Associations and fellow doctors, to support the doctor and his or her family in the face of threats or reprisals resulting from a refusal to condone the use of torture or other forms of cruel, inhuman or degrading treatment.

They are offered as guidelines and are universally accepted by all those maintaining the best traditions of medical practice. The 1980 edition of the British Medical Association Handbook of Medical Ethics makes particular reference to torture and, in the main, echoes the provisions of the Tokyo Declaration but there is one recommendation which has caused some disquiet.

It is unethical for a doctor to carry out an examination on a person before that person is interrogated under duress or torture. Even though the doctor takes no part in the interrogation or torture, his examination of the patient prior to interrogation could be interpreted as condoning it.

Events in Northern Ireland do not entirely support this view. Forensic Medical Officers there initiated the concept of the pre-interrogation medical examination on the grounds that an examination by an impartial and competent doctor before and after interrogation would make it possible to ascertain the truth of what happened in the intervening period. Thus, far from condoning torture, it would be an active means of exposing and preventing it. If, on the other hand, the intent is to assess fitness for torture, then, of course, it would be quite unacceptable, but this can easily be avoided if the results of the examination remain privy to the examiner.

\section{Awareness of the extent of the evil}

The unaffected and the complacent prefer not to acknowledge the existence of corrupt or evil practices. Ironically they become the first and easiest prey. They are also the least equipped to help their stricken fellow human beings. It is important, therefore, that we pay heed to all credible sources of information. The world continues to contract. No longer is malpractice in South America or Eastern Europe irrelevant to the daily lives of those in Western Europe or London.

Reports from well established religious organisations are usually shown to have substance but perhaps the most well informed and the least partisan is that remarkable institution Amnesty International. It is a non-political organisation whose main principles are independence, universality and impartiality. Embodied in its structure are separate medical groups with specific functions. We were not surprised to learn that they have examined subjects from South Korea, Greece and Uruguay but many of us were disturbed to learn that they found it necessary to examine citizens of a province in the United Kingdom.

Even in the most enlightened societies, sporadic cases are reported of ill-treatment towards those detained in penal and medical institutions. Every single instance is deserving of the most thorough inves- tigation, and if proven, warrants the most vehemen condemnation.

We know that human behaviour is infectious because man is an imitative creature. Let not evil ge unchecked lest it becomes accepted as the norm.

\section{Recognition of assailants}

It has already been pointed out that as medical prac $\frac{\frac{5}{5}}{5}$ titioners we have great responsibilities in the way w. exercise our cognitive skills. Other skills too have reley vance in the context of doctors and torture. There can be few medical practitioners who are truly exemp? from involvement but some are more likely to be affected than others. The police surgeon, the prison medical officer, the forensic psychiatrist and some doc tors in the armed services are particularly liable. Let us consider a few specific issues.

In the matter of medical fitness for employment, we may be able to exert influence in rejecting those pres 0 enting for employment as custodians of others. The prospective policeman, prison officer, psychiatric nurse, or member of the armed forces should not have sadomasochistic or other psychopathic propensities they should have personality and integrity sufficient t $\Theta$ resist easy persuasion by others; and ambition shoul $\bar{\phi}$ be distinguished clearly from craven power-seeking.

No less searching should be the scrutiny of the examiners themselves; at least by self-evaluation, better by our colleagues. We are no less exempt fromp the vagaries of human nature. Why should we not fom ourselves subjugating professional honesty to som so-called 'deserving cause' with the very suspect philoळ sophy of 'ends justifying means' controlling ou activities?

Other pitfalls may be encountered. How do we reaçํํำ if in obedience to the ethics of professional secrecy, we remain silent about knowledge gained from a profese sional relationship with a known torturer or murderer What of the plight of the doctor who is subject to statutory restriction, like the Official Secrets Act of Martial Law, which prevents him from honouring his professional code of conduct?

\section{Recognising the victim}

Diagnostic ability in recognising the effects of torture is another obligatory accomplishment. A study of the reports from those more familiar with the subjecto reveal unbelievable ingenuity in devising means to degrade, torment, and mortify others. The agent mays be physical, chemical or psychological - either singly or in combination. No part of the body is spareds though certain regions are favoured. It requires little imagination to guess those situations.

Often no useful purpose is served by wanton brutal: ity. Sleep deprivation, isolation, pharmacological tor ture, electrical torture, are often more effective an $\phi^{+}$ leave little in the way of evidence. Diagnosis may therefore, be extremely difficult if reliance is place ${ }^{\mathbb{P}}$ upon physical signs to corroborate allegations. 
As police surgeons, many of us have no little experience in recognising a form of torture known somewhat euphemistically as NAI (non-accidental injury). The characteristic diagnostic feature is not a simple burn, bruise, laceration, fracture or scald, but the aggregate picture of multiple and repeated injuries of particular character spanning weeks, months or even years. Doubtless other forms of torture have similar diagnostic features.

In assessing the effects of man's violence against man, forensic clinicians routinely apply the principle of the 'Theory of Interchange'. Macroscopic and microscopic trace evidence is sought, ie animate or inanimate particles left by, or taken from, a person or a locus. This is well illustrated in a case of alleged rape where seminal fluid may be retrieved from the complainant, and traces of vaginal secretion obtained from the accused.

A paramount consideration is an awareness of the possibility of an assault having taken place; and this applies particularly when examining those mentally deranged or fearful of accusing. Corroborative evidence is thus sought and the results are directly proportional to the ability of the examiner and the scientific and other specialist services at his disposal. It should go without saying that the first duty of the examiner, whatever his remit, is to institute any necessary treatment and relieve pain or suffering.

In those cases where torture is confirmed or suspected, all observations and the results of any biological tests are of little value unless recorded accurately and with the greatest possible detail. Any opinion should be carefully minuted and provision made to clearly distinguish it from factual evidence.

\section{Determination of a course of action}

Any subsequent course of action is entirely dependent upon the prevailing circumstances. To those practising in the United Kingdom, the following suggestions are offered. Confer with a respected colleague, if possible someone with experience in such matters. Good sense will guide your choice as to whether it is someone within the same establishment or completely unconnected. A favoured professional organisation such as the British Medical Association or the Association of Police Surgeons of Great Britain should be informed. Make provision for your evidence to be available to any agent of any court or tribunal likely to investigate the incident.

In extreme circumstances, conscience may dictate that non-professional representatives of the community, or even some international organisation, are apprised. Usually this step should only be contemplated after conferring with colleagues.

An important corollary of this aspect is the application of one of the recommendations of the Tokyo Declaration, viz - the support of colleagues threatened because of their condemnation of any inhuman treatment: provided, of course, that you are satisfied that the motives, competence, and integrity of those you support is beyond reproach lest you place your own integrity in jeopardy.

No good can result to others or yourself unless youre actions are impartial, honest and within the limits of your competence. Your judgment should not be pres judiced by personal emotional involvement. Those youp elect to judge should have your full confidence. Do no를 yourself pre-judge. Remember that the antagonists irfs any struggle can deceive and cheat. This includes thosę who, though oppressed, falsify and exaggerates accounts of their suffering. Self-inflicted injuries do occur; in fact extremists are known to receive and give? instruction in the art. Alleged victims may injure one another to justify their cause and substantiate wrongfup accusations. It is worth remembering the words of $\mathrm{W}$ Yeats:

The beggar has changed places; but the lash goes on $\omega$

Overt and oblique references have been made tळ Northern Ireland. It is fitting to make some mention of the involvement of the Association of Police Surgeonsof Great Britain. Early in 1979, Dr Robert Irwin, 尔 Belfast general practitioner, police surgeon and parto time prison medical officer became increasingly frus $\frac{\mathbb{D}}{3}$ trated with an apparent lack of interest shown by the authorities to his allegations of the ill-treatment of prisoners at the Castlereagh Holding Centre. $\vec{\emptyset}$

Rightly or wrongly, he eventually threw cautiongto the winds and voiced his opinion on a television p p. gramme. This act which resulted in banner headlines in the press, made 'Irwin' a household word, and $h e$ and his family experienced great personal distress.

Before, during and since that period of stress, th Association of Police Surgeons of Great Britain has given voluble support to his intent and, at a persona? level, encouragement to him and his family. In the name of the Association, letters were published in the National and Medical Press in defence of his actions and as an attempt to sustain a man who found himsel pitch-forked into a David and Goliath situation.

Dr Irwin's allegations were but one small facet of the disquiet which had continued over many years is Ulster and a Committee of Inquiry into Police Inter rogation Procedures in Northern Ireland was set up by the Government, (the so-called Bennett Committee) The findings were fair and far reaching and many recommendations have since been implemented.

It is pertinent to mention that implementation has created yet another moral dilemma. How far should the already overstretched resources of law and order bou further deployed to investigate alleged ill-treatment if by so doing, the murderers and terrorists are given greater freedom to pursue their evil activities? Those doctors concerned in the evaluation of alleged illo treatment have thus even greater responsibility in ensuring that their examinations are honest, impartial. competent, and performed with expedition.

Doctors somewhere, sometime, have and will become parties to the torture of others. The difference between active resistance and active assistance is cleax 
and well-defined but the graduations between these extremes may be slight and insidious. As a profession we must be watchful of the incidents and be clear in our own minds of our courses of action when confrontation comes. In the words of Sir John Powell, a 17 th century

Welsh Judge noted for his honesty:

He who has no inclination to learn more will be very apt

to think that he knows enough.

\section{JOURNAL OF MEDICAL ETHICS}

\section{Applications are invited for the}

\section{EDITORSHIP}

of the Journal of Medical Ethics, which will fall vacant during 1980/81. The Journal, published by the Society for the Study of Medical Ethics, is quarterly and has a worldwide circulation. The Society will take into consideration the multidisciplinary nature of the Journal in making this part-time appointment, for which an honorarium is offered. Further details from the Director, The Society for the Study of Medical Ethics, Tavistock House North, Tavistock Square, London WC1H 9LG. 